\title{
Review
}

\section{Review on Chronic Impacts of Carbon Monoxide Intoxication on Some Routine Vitreous and Blood Investigations}

\author{
Eni-yimini S.Agoro, PhD'*; Ebiere N. Ben-Wakama, MSc ${ }^{2}$; Peter W.Alabrah, MBBS, MSc ${ }^{3}$ \\ 'Department of Biochemistry, Federal University Otuoke, Yenagoa, Bayelsa, Nigeria \\ ${ }^{2}$ Bayelsa State College of Health Sciences and Technology, Bayelsa, Nigeria \\ ${ }^{3}$ Department of Obstetrics and Gynecology, Federal Medical Centre, Yenagoa, Bayelsa, Nigeria \\ *Corresponding author \\ Eni-yimini S.Agoro, PhD \\ Lecturer, Department of Biochemistry, Federal University Otuoke,Yenagoa, Bayelsa State, Nigeria;Tel. 08078404990; E-mail: enisagoro@gmail.com
}

\section{Article information}

Received: November $4^{\text {th }}, 2020$; Revised: November 19 ${ }^{\text {th }}, 2020$; Accepted: November 24 $4^{\text {th }}, 2020$; Published: November $27^{\text {th }}, 2020$

\section{Cite this article}

Agoro ES, Ben-Wakama EN, Alabrah PW. Review on chronic impacts of carbon monoxide intoxication on some routine vitreous and blood investigations. Toxicol Forensic Med Open J. 2020; 5(I): 16-25. doi: 10.17|40/TFMOJ-5-133

\section{ABSTRACT |}

Carbon monoxide (CO) is a toxic gas produced as a result of incomplete combustion of organic materials. The source of CO production is very common especially in nations that depend on power generating sets for electricity. Chronic disease is non-communicable and usually takes a longer time to manifest. Examples are kidney failure, diabetes mellitus, hypertension, cancer, and cardiac arrest. These diseases are now very common in society, not sparing the youthful population that was rare ab initio. The major difficulty in the containment of chronic diseases is the inability to establish a definitive causative agent. The definite causative agent is important in public health and management of chronic diseases. Preventive medicine is anchored on establishing the causative agent of a disease. Without knowing the causative agent of a disease, the path to prevention becomes very cumbersome. The knowledge of the causative agent of a disease is the bedrock of preventive medicine and public health. Several reasons such as lifestyle modification, hereditary, climate change, nutrition or aging have been adduced as the cause of chronic diseases. These reasons are quite weak and not definite. The exact causative agent(s) of chronic diseases is a conundrum that needs a deliberate study and review so as to enhance definite diagnosis, preventive measures and appropriate therapeutic intervention. Measurement of biochemical and haematological parameters are employed in disease diagnosis and management. Alterations of these parameters are used to identify chronic diseases and also form part of an alarm system of a potential breakdown of the normal functioning of the body. The effect of chronic CO intoxication on these parameters could be of importance in establishing causative agent(s) of diseases that are for long opaque and non-definite. This review was therefore designed to interrogate various narratives, meta-analysis, and researches on this subject. Explicit knowledge of the pattern or presentation of biochemical and haematological parameters arising from chronic CO intoxication could be of great importance in preventive medicine, disease diagnosis and appropriate therapeutic intervention.

\section{Keywords}

Biochemical parameters; Haematological parameters; Chronic diseases; Carbon monoxide; Chronic intoxication.

\section{INTRODUCTION}

C arbon monoxide (CO) is a noxious, tasteless, colourless, odourless and nonirritant gas formed as a result of the incomplete combustion of organic materials due to insufficient supply of oxygen to enable complete oxidation to carbon dioxide $\left(\mathrm{CO}_{2}\right){ }^{1}$ It is nicknamed angelic gas due to its euphoric and nerves relaxation nature. The euphoric nature originates from nerve relaxation and oxygen denial to vital organs such as the brain that aids consciousness and rapid response to stimuli.
Carbon monoxide has an affinity of about 200 to 300 times for haemoglobin $(\mathrm{Hb})$ than oxygen $\left(\mathrm{O}_{2}\right)$. The reaction between $\mathrm{CO}$ and $\mathrm{Hb}$ results in the formation of a more stable molecule called carboxyhaemoglobin. ${ }^{1}$ The formation of carboxyhaemoglobin renders haemoglobin incapable of carrying and transporting oxygen; resulting in tissue hypoxia. As long as $\mathrm{CO}$ is present in the atmosphere, it goes on bonding with haemoglobin, leading to acute chemical asphyxia. ${ }^{1}$ The denial of the body of oxygen is very precarious as most organs survive on its availability. This attribute of occlusion of the body to oxygen supply is the 
basis of the classification of $\mathrm{CO}$ as an asphyxiant.

The mechanism of action of carbon monoxide is not only perpetrated by decreasing the concentration of oxygen content of blood but also reducing oxygen availability to tissues. The cumulative decreased concentration and non-availability of oxygen to tissues lead to a greater degree of tissue hypoxia than an equivalent reduction in oxyhaemoglobin caused by hypoxia. ${ }^{2}$ Carbon monoxide also binds to other haem proteins, such as myoglobin and mitochondrial cytochrome oxidase a3, which further limits oxygen use when tissue partial oxygen pressure $\left(\mathrm{PO}_{2}\right)$ is low.

The pathophysiology of CO poisoning is a derivation of hypoxia which usually cut off or reduce the supply of oxygen to vital organs that control the entire body's systems. Organs most impacted are the brain and heart. ${ }^{3}$ Others are kidney, pancreas and liver. The concentration of CO exceeding $100 \mathrm{ppm}$ could be very harmful to humans and animals alike. Symptoms of CO poisoning are dependent on the concentration and duration of exposure. Symptoms such as dizziness, sweating, headache, dim vision, tremor and loss of consciousness are most common. ${ }^{4}$

Carbon monoxide poisoning is the inhalation of large quantities of $\mathrm{CO}$ that is harmful to the body. This could result in morbidity or mortality based on the concentration of CO inhaled, the health status and age of the victim. According to the U.S. Environmental Protection Agency (EPA), major sources of carbon monoxide include generators and other gasoline powered equipment, and automobile exhaust.

The minimum power supply need in Nigeria is estimated to be 100,000 megawatt, yet production is currently at $5 \%$ of the minimum need. ${ }^{5-7}$ This great deficit of approximately 95,000 megawatt has elicited the use of generating sets as an alternative power source in homes, in industries and big infrastructures, and organizations. This has created unrestrained inhalation of $\mathrm{CO}$ with its attendant health implications. The bad transport network and poor regulatory system to gas emissions have further worsened the exposure to $\mathrm{CO}$ by the citizens of Nigeria.

The leap in chronic non-communicable diseases in $\mathrm{Ni}$ geria is of major public health concern. Exposures to toxic gases repeatedly could be associated with chronic diseases as shown in literature. This gap calls for a deliberate review of the literature in relation to the alterations of biochemical and haematological parameters occasioned by the incessant inhalation of $\mathrm{CO}$. Hence, this review is designed to explore the various frontiers of biochemical and haematological compromises resulting from chronic CO intoxication. The compromises could be used in defining idiopathic diseases that are of public health concern in Nigeria and the world at large.

\section{SERUM AND VITREOUS TOTAL PROTEIN}

The human body contains thousands of different proteins. Many are structural elements of cells or organized tissues; others are soluble in intracellular or extracellular fluids. The proteins most amenable to routine laboratory evaluations are those in blood, vitreous humour, urine, cerebrospinal fluid (CSF), amniotic fluid, saliva and peritoneal or pleural fluids. ${ }^{8}$ Total protein majorly represents the sum of albumin and globulins. Soluble proteins are used in the diagnosis and management of several systemic disorders or abnormalities.

A study spearheaded by Dr. E.S. Agoro revealed a significant decrease in concentrations of serum and vitreous total protein and globulin and, an increase in $\mathrm{A} / \mathrm{G}$ ratio in rabbits consistently exposed to mild CO concentration for a long period Agoro et al. ${ }^{9}$ They attributed the decrease to immune-suppression. Globulins are immune proteins produced in response to infection, inflammation or toxicity. The authors stated that consistent exposure to $\mathrm{CO}$ could result in depression of the immune system which was reflected in the subsequent fall in globulin concentration. A fall in globulin concentration and an increase in the $A / G$ ratio have been established as a pattern presented in immune depression or suppression. ${ }^{10}$

However, another study has revealed that $\mathrm{CO}$ poisoning could create a complex pattern of rises in acute phase reactants and proteins associated with inflammatory responses, including chemokines/cytokines and interleukins. Fourteen protein concentrations were shown to be significantly different from control in all CO groups, including patients with nominal carboxyhaemoglobin elevations and relatively brief intervals of exposure. ${ }^{11}$

The above lines of thoughts have established the palpable impact of chronic CO intoxication on the immune system. Hence, chronic intoxication of $\mathrm{CO}$ has the preponderance of opening the floodgates of diseases associated with immune compromise.

\section{SERUM AND VITREOUS LIPID PROFILE}

The term lipid applies to a class of compounds insoluble in water, but soluble in organic solvents such as chloroform. Chemically, lipids yield fatty acids on hydrolysis, or can react with complex alcohols to form esters. ${ }^{2}$ Lipid profile or panel is a battery of investigations that serve as an initial broad medical screening tool for abnormalities in lipids, such as cholesterol and triglycerides. Major investigations constituting lipid profile includes total cholesterol, triglyceride, high-density lipoprotein (HDL), and low-density lipoprotein (LDL).

The long-term effect of $\mathrm{CO}$ on serum and vitreous lipid profiles could be used to explain the rising incidence of heart diseases and cardiac failures. A study observed a decrease in heart rate and pulse pressure in isolated rat hearts exposed to $\mathrm{CO}$ intoxication. ${ }^{12}$ Carbon monoxide exposure has also been implicated in the process of atherosclerosis. Studies using rabbits and monkeys have reported an accumulation of cholesterol in the aorta, coronary arteries and endothelial tissues resulting from $\mathrm{CO}$ exposure. ${ }^{13}$ In the same vein, in vitro studies on $\mathrm{CO}$ exposure have been demonstrated to have a deleterious effect on the circulatory system. ${ }^{14-17}$

The investigation of the impact of gas flaring on the lipid profile of the dwellers of the Niger Delta region of Nigeria re- 
vealed amazing results. ${ }^{18}$ They revealed that serum concentrations of triglycerides, LDL, and very low-density lipoproteins (VLDL) were elevated compared to the control. In the same study, they revealed a decrease in the concentration of serum HDL. Carbon monoxide is the major component of gas flares; hence, it could infer that the elevations of the lipids as observed could be attributable to the concentration of $\mathrm{CO}$ in the environment.

Furthermore, the cholesterol component of LDL concentration was discovered to increase in concentration due to carbon monoxide poisoning as posited by Alcindor et al. ${ }^{19}$ Thus, the aggravating effect of carbon monoxide exposure on the atherogenic properties of this lipoprotein could accelerate the development of atherosclerosis in rabbits.

In contrast, a study showed a significant decrease in the concentration of serum and vitreous lipid profiles, except for triacylglycerol. ${ }^{20}$ The authors argued that the fall in the concentration of plasma and vitreous lipid profile (except serum triglyceride (TG)) could be attributable to massive infiltration of lipids into the body's cells or as a result of oxidative peroxidation originating from free radicals generated by $\mathrm{CO}$.

The above narratives on the effect of chronic CO intoxication on lipid profile are a clear exposition of the harmful effect of $\mathrm{CO}$ on the entire body functions. Dysfunctional lipid profile is clinically an implication of circulatory and insulation distortions, which is evident in countless disease conditions.

\section{SERUM AND VITREOUS ELECTROLYTES}

Electrolytes are substances that become ions in solution and acquire the capacity to conduct electric energy. ${ }^{20}$ They are present in the human body, and its balance is essential for normal life sustenance.

Electrolytes regulate the functioning of muscles, and nerves in the body, and many more sensory activities. Aside from those, the maintenance of blood pressure and acidity are controlled by electrolytes. Distortions of electrolyte concentrations lead to a sluicegate of numerous pathological conditions.

The pattern of electrolyte concentrations in the serum and vitreous humours is still debatable due to the paucity of research findings. A study on the pattern of some serum and vitreous electrolyte concentrations were brought to the fore by Agoro et al. ${ }^{20}$ In the exposition, they revealed that chronic intoxication of CO has the propensity of creating electrolyte imbalances. Furthermore, they posited that serum $\mathrm{Na}$, non-ionized calcium (nCa), ionized calcium (Ca), total calcium (TCa), concentrations were significantly raised proportionately to the increase in the duration of $\mathrm{CO}$ exposure, whereas the $\mathrm{pH}$ activity decreased. In the same vein, vitreous humour chemistry data revealed significant decreases in $\mathrm{pH}$ activity and concentrations of potassium, $\mathrm{TCa}, \mathrm{nCa}$, and $\mathrm{Ca}$.

The imbalances in electrolyte concentrations observed could be deleterious and a pointer to the leap in chronic idiopathic diseases rampancy in countries that disregard to CO emission control and regulation.

\section{SERUM AND VITREOUS RENAL FUNCTION BIOMARKERS}

Renal function markers are used for the diagnosis and management of renal diseases. The most commonly used renal function markers are urea, creatinine, and uric acid. An increase in the concentration of these markers indicates possible renal abnormalities. Urea had been shown to be one of the most stable of the vitreous constituents tested in postmortem. ${ }^{21}$ The vitreous value of urea is a reflection of antemortem value as posited by Madea and Musshoff..$^{22}$ This was also supported by Agoro et al. ${ }^{23}$

The pattern of presentation of serum and vitreous renal function markers occasioned by chronic intoxication of $\mathrm{CO}$ is still hazy. One of the earliest callers to this subject revealed a rise in the concentration of serum creatinine as the duration of exposure to CO increases, contrarily uric acid (UA) concentrations significantly decreased. ${ }^{20}$ In the same vein, vitreous humour chemistry data revealed a significant increase in the concentration of creatinine and urea, whereas uric acid significantly decreased. ${ }^{20}$

The compromises observed indicate the direct negative impact of $\mathrm{CO}$ on the normal architecture of the kidney.

\section{SERUM AND VITREOUS CARDIAC BIOMARKERS}

Cardiac biomarkers are measured to evaluate the functionality of the heart and stratification of risks associated with cardiac dysfunction such as suspected acute coronary syndrome (ACS). ${ }^{2}$ Cardiac biomarkers abound, but the commonly patronized ones are troponin, creatine kinase (CK-MB), lactate dehydrogenase (LDH), and aspartate aminotransferase (AST). ${ }^{24,25}$ Others are myoglobin $(\mathrm{Mb})$, ischemia-modified albumin (IMA), pro-brain natriuretic peptide, and glycogen phosphorylase isoenzyme BB. ${ }^{24,25}$

The correlation between chronic $\mathrm{CO}$ intoxication and cardiac dysfunction is still not definite in biomedical literature. However, a handful of studies have shown diverging perspectives. A study as posited by Whang and $\mathrm{Choi}^{26}$ observed an increase in activities of serum creatine kinase and lactate dehydrogenase in carbon monoxide-intoxicated patients. In the same vein, Davutoglu et $\mathrm{a}^{27}$ stated that acute carbon monoxide (CO) poisoning may cause cardiotoxicity but troponin, $\mathrm{CK}$, and $\mathrm{CK}-\mathrm{MB}$ concentrations were not statistically significant between groups as observed in sufferers of carbon monoxide intoxication. A study using an animal model showed an elevation in the activities of vitreous and serum $\mathrm{LDH}$ and $\mathrm{CK}$ in rabbits chronically exposed to $\mathrm{CO} .^{20}$ Another study also reported an increase in activities of serum $\mathrm{LDH}$ and $\mathrm{CK}$ due to chronic CO intoxication. ${ }^{28}$ Serum lactate dehydrogenase $(\mathrm{LDH})$, creatine kinase $(\mathrm{CK})$ and aspartate aminotranferase (AST) are important biochemical parameters used in diagnosing cardiotoxicity and cardiac dysfunction. ${ }^{25,26}$ The increases as observed in a couple of studies have further shown that chronic CO intoxication could be injurious to the cardiac system. 


\section{SERUM AND VITREOUS OXIDATIVE STRESS BIOMARKERS}

Oxidative stress is a condition characterized by elevated concentrations of intracellular reactive oxygen species (ROS), which are the progenitors of free radicals. ${ }^{29}$ Reactive oxygen species such as superoxide anion (O-) and hydroxyl radicals (OH-) are capable of reacting with and damaging proteins, lipids and deoxyribonucleic acid (DNA). Enzymes related to the study of oxidative stress includes catalase, superoxide dismutases (SOD), glutathione peroxidases (GPX), nitric oxide synthase (eNOS, iNOS, and nNOS), peroxiredoxins, thioredoxins (Trx), and more.

Oxidative stress is the distortion of the equilibrium that exists between synthesis of reactive oxygen species and the efficiency of the biological systems to neutralize the reactive intermediates or repair the resultant damage Severe oxidative stress can cause cell death or necrosis, and even moderate oxidation can trigger apoptosis. ${ }^{30,31}$

Agoro et $\mathrm{al}^{32}$ did elaborate research on the oxidative stress status of rabbits exposed to chronic $\mathrm{CO}$ intoxication. The results of the study revealed a significant increase in the concentration of malondialdehyde (MDA) both in the serum and vitreous as the duration of $\mathrm{CO}$ exposure increased. Similar findings have also been reported by Muhammad and Fredrick, ${ }^{5}$ and Ismail ${ }^{33}$ though the severity of exposure could not be ascertained. Contradictory reports supporting non-significant influence of $\mathrm{CO}$ intoxication on MDA concentration were observed by Thom et $\mathrm{al}^{34}$ and Guan et al..$^{35}$

Moreover, Agoro et $\mathrm{al}^{32}$ reported a decrease in the activity of SOD both in the serum and vitreous humor. The position of Agoro et $\mathrm{al}^{32}$ was in tandem with those of Ismail et $\mathrm{al}^{33}$ and Patel et al. ${ }^{36}$ However, Piantaosi et al, ${ }^{37}$ Hamed et $\mathrm{al}^{38}$ and Kavakli et al ${ }^{39}$ disagreed with the above findings.

Furthermore, catalase activities exhibited a significant increase in serum and a decrease in the vitreous. ${ }^{32}$ The discrepancy observed was alluded to by the authors to compartmental difference, accessibility or portal of entry difference. A glutathione concentration was seen to decrease in the serum and increased in the vitreous, respectively, as indicated by Agoro et al. ${ }^{32}$

The above discourse bared that chronic CO intoxication has palpable effects on oxidative stress. Oxidative stress is a phenomenon used by several biological and chemical agents in altering body chemistry and physiological balance. This has brought to bear that chronic CO intoxication could be an orifice to a wide range of pathological derangements and chronic diseases.

\section{SERUM LIVER FUNCTION PARAMETERS}

The liver performs several important functions that involve excretory, synthetic or detoxifying mechanisms. Investigations conducted to ascertain the status of the liver is called liver function test (LFT). ${ }^{40}$ These tests include prothrombin time (PT/INR), aPTT, albumin, bilirubin (direct and indirect), liver aminotransferases (AST or and ALT), alkaline phosphatase (ALP), gamma glutamyl transferase (GGT) and 5'-Nucleotidase, and others. ${ }^{41,42}$

Alterations of the above parameters are indicative of liver dysfunction. Many biological and chemical agents have harmful effects on the liver and its accessory organs. The carbon monoxide effect on the liver has been researched by a handful of researchers. A study by Nanji et $\mathrm{al}^{43}$ indicated a significant increase in serum ALT activity in an animal model exposed to CO-ethanol. Furthermore, electron microscopy revealed a greater degree of cell necrosis in the CO-exposed group, which explained the significantly higher ALT activity in these animals. Another researcher observed a decrease in alkaline phosphatase activity and an increase in acid phosphatase activity after 7 -days of intoxication with $\mathrm{CO} .{ }^{44}$

The stance of Agoroand Wankasi ${ }^{28}$ on this subject revealed a significant increase in activities/concentrations of serum aspartate aminotransferases (AST), alanine aminotransferases (ALT), alkaline phosphatase (ALP), total and conjugated bilirubin and albumin/globulin ratio, whereas serum total protein and globulin decreased significantly when studied animal were consistently exposed to moderate $\mathrm{CO}$ concentration for months.

However, a study has shown that at a low concentration of carbon monoxide, bilirubin exerts an anti-oxidative function, hence protecting cells and tissues from hepatic injuries. ${ }^{45}$ Furthermore, at a moderate carbon monoxide concentration, bilirubin served an effective buffer function. ${ }^{46,47}$

The above submissions are pointing toward a harmful impact of consistent exposure of $\mathrm{CO}$ on the liver and its accessory organs.

\section{HAEMATOLOGICAL PARAMETERS}

Haematological parameters are vital investigations used for the diagnosis and management of diseases associated with blood. Blood examination is also very essential to the diagnosis of poisoning cases and its attendant management. Some metabolites and cells found in the blood aid in diagnosis of diseases and toxicities. This is due to the vast role blood plays in physiology, nutrition and pathology of human or animal. Haemaological parameters commonly employed in disease and poisoning diagnosis and management are haemoglobin concentration ( $\mathrm{Hb}$ ), packed cell volume (PCV), red blood cells (RBC), white blood cell (WBC), platelets, mean corpusculars volume or cell (MCV), mean corpuscular haemoglobin $(\mathrm{MCH})$ and mean corpuscular haemoglobin concentration (MCHC). ${ }^{48}$ These parameters are very vulnerable to alterations by several factors and conditions due to the circulatory nature of the body.

A study involving the use of rabbits revealed a significant increase in concentrations of $\mathrm{RBC}, \mathrm{Hb}$ and $\mathrm{PCV}$ on day one and was consistently high till day 5 after an intraperitoneal injection of $\mathrm{CO}$ at regular interval. ${ }^{49}$ In another study using cigarette smokers, the packed cell volume and red cells were increased due to hypoxic 
mechanism of which $\mathrm{CO}$ constitutes the major component. ${ }^{50}$

In a similar study, the concentrations of $\mathrm{Hb}, \mathrm{RBC}$ count and PCV in age-matched smokers were compared with those of nonsmokers. The findings explicitly showed a significant increase $(p<0.5,0.01$ or 0.001$)$ in the concentrations of $\mathrm{Hb}, \mathrm{RBC}$ count, $\mathrm{PCV}$, and $\mathrm{MCH}$ in the various groups of smokers compared to controls which were nonsmokers of same age groups. ${ }^{51}$

Vanuxem et $\mathrm{al}^{52}$ showed a characteristic haematological change in $\mathrm{CO}$ intoxication as a toxic change of WBCs, such as initial leukocytosis and neutrophilia. This was supported by Whang and $\mathrm{Choi}^{53}$ who also showed that WBC counts were increased. Sung-Soo and II-Saing ${ }^{54}$ also observed an increase in the count and that "leukocytosis mainly neutrophilic, observed during the first few days to be a physiological phenomenon due to a stressful situation, such as hypoxia. The same finding was achieved by Ganesh and Saravanan, ${ }^{50}$ using cigarette smokers as subjects.

In a correlational study between carboxyhaemoglobin concentration and platelets, the result showed a decrease in platelets. ${ }^{55}$ The finding of Oscar ${ }^{56}$ was similar to that of Suphan and Jamsai, ${ }^{55}$ but further posited that the decrease was occasioned by the inhibition of calcium. It has also been established that carbon monoxide (CO) inhibits human platelet aggregation triggered with threshold concentrations of agonists like arachidonate, ADP, collagen, thrombin, or the prostaglandin endoperoxide analogue $\mathrm{U} 46619 .{ }^{57}$
In a study, rats were continuously exposed to $500 \mathrm{ppm}$ $\mathrm{CO}$ for 42-days. This was reflected in the blood indices: the MCHC, $\mathrm{MCH}$, and MCV. MCHC fell $6 \%$ by the fifth day of exposure, while $\mathrm{MCH}$ and MCV increased $11 \%$ and $16 \%$, respectively, by the seventh day. The mean cell haemoglobin concentration returned to control concentration by the thirteenth day, while $\mathrm{MCH}$ and $\mathrm{MCV}$ remained elevated until the twenty-fifth day of $\mathrm{CO}$ exposure. During "stable" polycythemia both $\mathrm{MCHC}$ and $\mathrm{MCH}$ were depressed, while MCV concentration was slightly elevated above the controls. ${ }^{58}$

In a study by Muhammad, et $\mathrm{al}^{51}$ the values of red cell indices in age-matched smokers were compared with nonsmokers. The results of the increase in values of MCV and MCHC were found less marked and non-significant $(p>0.05)$.

Findings on chronic carbon monoxide exposure, as shown by Agoro et $\mathrm{al}^{59}$ indicated that RBCs, lymphocytes and basophils were significantly raised, whereas platelets, white blood cell, neutrophils, monocytes, eosinophils, $\mathrm{MCV}, \mathrm{MCH}$ and $\mathrm{MCHC}$ were significantly decreased. In their conclusion, they posited that chronic $\mathrm{CO}$ inhalation has the predisposition of distorting haematological profiles.

\section{CONCLUSION}

This review critically focuses on the available meta-analyzed data pertaining to the impact of chronic $\mathrm{CO}$ exposures on routine biochemical and haematological parameters. These parameters are

\begin{tabular}{|c|c|c|c|c|c|c|}
\hline \multicolumn{7}{|l|}{ Parameter (s) } \\
\hline & Increase & Source & Decrease & Source & NSD & Source \\
\hline Carboxyhaemoglobin (\%) & $\mathbf{1}$ & 11 & & & & \\
\hline Urea $(\mu \mathrm{mol} / \mathrm{L})$ & & & & & $x$ & 20 \\
\hline Creatinine $(\mu \mathrm{mol} / \mathrm{L})$ & $\mathbf{1}$ & 20 & & & & \\
\hline Uric Acid $(\mu \mathrm{mol} / \mathrm{L})$ & & & $\downarrow$ & 20 & & \\
\hline Sodium $(\mu \mathrm{mol} / \mathrm{l})$ & $\mathbf{1}$ & 20 & & & & \\
\hline Potassium $(\mu \mathrm{mol} / \mathrm{l})$ & & & $\downarrow$ & 20 & & \\
\hline Chloride $(\mu \mathrm{mol} / \mathrm{l})$ & & & & & $x$ & 20 \\
\hline $\mathrm{Ph}$ & & & $\downarrow$ & 20 & & \\
\hline Calcium $(\mu \mathrm{mol} / \mathrm{l})$ & $\boldsymbol{1}$ & 20 & & & & \\
\hline nCalcium $(\mu \mathrm{mol} / \mathrm{l})$ & $\mathbf{t}$ & 20 & & & & \\
\hline Total Calcium $(\mu \mathrm{mol} / \mathrm{l})$ & $\mathbf{T}$ & 20 & & & & \\
\hline Total Cholesterol (mmol/L) & $\uparrow$ & 18 & $\downarrow$ & 32 & & \\
\hline Triacylglycerol (mmol/L) & $\mathbf{1}$ & 18,20 & & & & \\
\hline $\mathrm{HDL}(\mathrm{mmol} / \mathrm{L})$ & & & $\downarrow$ & 18,32 & & \\
\hline $\mathrm{LDL}(\mathrm{mmol} / \mathrm{L})$ & $\mathbf{1}$ & 18,19 & $\downarrow$ & 32 & & \\
\hline VLDL (mmol/L) & $\boldsymbol{1}$ & & $\downarrow$ & 32 & & \\
\hline Total Protein(g/L) & & & $\downarrow$ & 9 & & \\
\hline Albumin $(\mathrm{g} / \mathrm{L})$ & & & & & $x$ & 9 \\
\hline Globulin (g/L) & & & $\downarrow$ & 9 & & \\
\hline
\end{tabular}




\begin{tabular}{|c|c|c|c|c|c|c|}
\hline A/G Ratio & $\boldsymbol{\top}$ & 9 & & & & \\
\hline Creatine Kinase (U/L) & $\boldsymbol{\top}$ & $20,26,28$ & & & $x$ & 27 \\
\hline Lactate Dehydrogenase (U/L) & $\mathbf{1}$ & $20,26,28$ & Decrease & & & \\
\hline Glutathione $(\mu / \mathrm{mg})$ & $\downarrow$ & 5,33 & $\downarrow$ & $32,34,35$ & & \\
\hline $\mathrm{SOD}(\mu / \mathrm{mg})$ & $\downarrow$ & 33,26 & $\downarrow$ & $32,34,35$ & & \\
\hline CATALASE $(\mu / \mathrm{mg})$ & $\uparrow$ & 32 & & & & \\
\hline $\mathrm{MDA}(\mathrm{mmol} / \mathrm{mg})$ & $\mathbf{T}$ & 32 & $\downarrow$ & 34,35 & & \\
\hline AST (U/L) & $\boldsymbol{\top}$ & 28 & & & & \\
\hline ALT ( U/L) & $\mathbf{t}$ & 28,43 & & & & \\
\hline AST/ALT & $\boldsymbol{\top}$ & 28 & & & & \\
\hline $\operatorname{ALP}(U / L)$ & $\boldsymbol{\top}$ & 28 & $\downarrow$ & 44 & & \\
\hline $\mathrm{ACP}(\mathrm{U} / \mathrm{L})$ & $\mathbf{t}$ & 44 & & & & \\
\hline $\mathrm{TB}(\mu \mathrm{mol} / \mathrm{L})$ & $\boldsymbol{\uparrow}$ & 28 & & & & \\
\hline $\mathrm{CB}(\mu \mathrm{mol} / \mathrm{L})$ & $\mathbf{T}$ & 28 & & & & \\
\hline UB $(\mu \mathrm{mol} / \mathrm{L})$ & & & & & $x$ & 28 \\
\hline HAEMOGLOBIN (g/dl) & $\mathbf{T}$ & 49,51 & & & $x$ & 59 \\
\hline PCV (\%) & $\uparrow$ & 49,51 & & & $x$ & 59 \\
\hline $\mathrm{RBC}(\times 1012 / \mathrm{L})$ & $\mathbf{1}$ & 49,51 & & & & \\
\hline WBC $(\times 109 / L)$ & $\uparrow$ & $50,53,54$ & $\downarrow$ & 59 & & \\
\hline PLATELET $(x$ 1012/L) & $\downarrow$ & $55,56,59$ & & & & \\
\hline $\operatorname{MCV}(f)$ & $\downarrow$ & 59 & & & & \\
\hline $\mathrm{MCH}(\mathrm{pg})$ & $\boldsymbol{\uparrow}$ & 51 & $\downarrow$ & 59 & $x$ & 51 \\
\hline $\mathrm{MCHC}(\mathrm{g} / \mathrm{dl})$ & $\mathbf{t}$ & 59 & & & $x$ & 51 \\
\hline NEUTROPHIL (\%) & $\mathbf{1}$ & 52 & $\downarrow$ & 59 & & \\
\hline LYMPHOCYTE (\%) & $\mathbf{t}$ & 59 & & & & \\
\hline MONOCYTE (\%) & & & $\downarrow$ & 59 & & \\
\hline EOSINOPHIL (\%) & & & $\downarrow$ & 59 & & \\
\hline BASOPHIL (\%) & & & & & $x$ & 59 \\
\hline \multicolumn{7}{|c|}{$\boldsymbol{\uparrow}=$ significantly increased; $\mathbb{I}=$ significantly decreased } \\
\hline \multicolumn{7}{|c|}{$\begin{array}{l}X=\text { Not significant, NSD=Not significantly different, } n \text { Calcium=Non-ionized calcium, HDL-High density lipoprotein, LDL-Low } \\
\text { density lipoprotein, VLDL-Very low density lipoprotein, A/G-Albumin/globulin ratio, SOD-superoxide dismutase, MDA- } \\
\text { Malondialdehyde, AST=-Aspartate aminotransferase, ALT-Alanine aminotransferase, ACP-Acid phosphatase,TB-Total bilirubin } \\
\text { CB-Conjugated bilirubin, UB-Unconjugated bilirubin, MCV-Mean cell volume, MCHC-Mean cell haemoglobin concentration, } \\
\text { WBC-White blood cell, RBC-Red blood cell. }\end{array}$} \\
\hline
\end{tabular}

the pivot of the diagnosis and identification of diseases. Table 1 and 2 summarized some of the presentations of biochemical and haematological parameters in the serum and vitreous occasioned by chronic $\mathrm{CO}$ intoxication respectively.

The findings explicitly revealed a gross harmful effect of chronic CO intoxication on most of the parameters reviewed. Furthermore, the compromises seen in the parameters are indicative of palpable negative consequences of $\mathrm{CO}$ intoxication on the body's systems. This could be exemplified with the data on oxidative stress indicators. Oxidative stress is a known tool used by several diseases in upsetting normal functioning of the body. Similarly, the data on renal function and cardiac biomarkers are indicative of the potentialities of chronic $\mathrm{CO}$ intoxication in causing renal and cardiac dysfunction, respectively. The same pattern was observed in liver function parameters that showed the vulnerability of hepatic and post-hepatic tissues to distortions by chronic CO intoxication. Haematological parameters were not spared as alterations were noted in some parameters such as $\mathrm{RBC}, \mathrm{Hb}$, platelets, differentials and some red cell indices. The alterations in biochemical and physiological parameters point to the susceptibility of the entire body to chronic $\mathrm{CO}$ exposure, and the changes resemble chronic diseases such as cardiac dysfunction, diabetes mellitus, renal failure and liver insufficiency. The compromise of the immune system is another worrisome submission of this review as immune suppression or depression was noted. Immune suppression makes the body vulnerable to several diseases and infection that could be easily eliminated by the body defense system. Summarily, the review has shown that exposure to chronic $\mathrm{CO}$ intoxication is deadly and harmful. The need for tight regulatory measures on $\mathrm{CO}$ emission is apt. Regulatory measures should be legally instituted and culprits punished to serve as a deterrent. Furthermore, more 


\begin{tabular}{|c|c|c|c|c|c|c|}
\hline \multicolumn{7}{|l|}{ Parameter (s) } \\
\hline & Increase & Source & Decrease & Source & NSD & Source \\
\hline Urea $(\mu \mathrm{mol} / \mathrm{L})$ & $\mathbf{T}$ & 20 & & & & \\
\hline Creatinine $(\mu \mathrm{mol} / \mathrm{L})$ & $\mathbf{T}$ & 20 & & & & \\
\hline Uric Acid ( $\mu \mathrm{mol} / \mathrm{L})$ & $\downarrow$ & 20 & & & & \\
\hline \multicolumn{2}{|l|}{ Sodium $(\mu \mathrm{mol} / \mathrm{l})$} & & & & $x$ & 20 \\
\hline \multicolumn{2}{|l|}{ Potassium $(\mu \mathrm{mol} / \mathrm{l})$} & & I & 20 & & \\
\hline \multicolumn{2}{|l|}{ Chloride $(\mu \mathrm{mol} / \mathrm{l})$} & & & & $x$ & 20 \\
\hline \multicolumn{2}{|l|}{$\mathrm{Ph}$} & & $\downarrow$ & 20 & & \\
\hline \multicolumn{2}{|l|}{ Calcium $(\mu \mathrm{mol} / \mathrm{l})$} & & $\downarrow$ & 20 & & \\
\hline \multicolumn{2}{|l|}{ nCalcium ( $\mu \mathrm{mol} / \mathrm{l})$} & & $\downarrow$ & 20 & & \\
\hline \multicolumn{2}{|l|}{ Total Calcium $(\mu \mathrm{mol} / \mathrm{l})$} & & $\downarrow$ & 20 & & \\
\hline \multicolumn{2}{|l|}{ Total Cholesterol (mmol/L) } & & $\downarrow$ & 32 & & \\
\hline \multicolumn{2}{|l|}{ Triacylglycerol (mmol/L) } & 32 & & & & \\
\hline \multicolumn{2}{|l|}{$\mathrm{HDL}(\mathrm{mmol} / \mathrm{L})$} & & & 32 & & \\
\hline \multicolumn{2}{|l|}{ LDL (mmol/L) } & & $\downarrow$ & 32 & & \\
\hline \multicolumn{2}{|l|}{ VLDL (mmol/L) } & & $\downarrow$ & 32 & & \\
\hline \multicolumn{2}{|l|}{ Total Protein $(g / L)$} & & $\downarrow$ & 32 & & \\
\hline \multicolumn{2}{|l|}{ Albumin $(g / L)$} & & & & $\mathrm{x}$ & 32 \\
\hline \multicolumn{2}{|l|}{ Globulin $(g / L)$} & & $\downarrow$ & 32 & & \\
\hline A/G Ratio & $\boldsymbol{\uparrow}$ & 32 & & & & \\
\hline Creatine Kinase (U/L) & $\mathbf{1}$ & 20 & & & & \\
\hline Lactate Dehydrogenase (U/L) & $\mathbf{t}$ & 20 & & & & \\
\hline Glutathione $(\mu / \mathrm{mg})$ & $\mathbf{\uparrow}$ & 32 & & & & \\
\hline \multicolumn{2}{|l|}{$\operatorname{SOD}(\mu / \mathrm{mg})$} & & $\downarrow$ & 32 & & \\
\hline \multicolumn{2}{|l|}{ CATALASE $(\mu / \mathrm{mg})$} & & $\downarrow$ & 32 & & \\
\hline MDA (mmol/mg) & $\mathbf{t}$ & 32 & & & & \\
\hline \multicolumn{7}{|c|}{$\mathbf{\mathbf { I }}=$ significantly increased; I=significantly decreased } \\
\hline \multicolumn{7}{|c|}{$\begin{array}{l}X=\text { Not Significant, NSD=Not Significantly different, } n \text { Calcium=Non-ionized calcium, HDL-High density lipoprotein, LDL-low } \\
\text { density lipoprotein,VLDL-very low density lipoprotein, A/G-Albumin/globulin ratio, SOD-Superoxide dismutase, } \\
\text { MDA-Malondialdehyde }\end{array}$} \\
\hline
\end{tabular}

studies on this subject using the human model to unravel the evil of chronic CO intoxication are solicited. This will, in no measure, enhance public health surveillance and reduce the leap in idiopathic and chronic diseases.

\section{FUNDING}

No funding was granted from any source.

\section{CONFLICTS OF INTEREST}

The authors declare that they have no conflicts of interest.

\section{REFERENCES}

1. Nageshkumar GR. Cardiac poisons. In: Forensic Medicine and Toxi- 5. Muhammad YG, Fredrick OU. The effect of exhaust fumes on cology. New Delhi, India: Jaypee Brothers Medical Publishers; 2006: 425-432.

2. Carl AB, Edward RA. Analytes of haemoglobin metabolismporphyrin, iron, and bilirubin. In: Fundamentals of Clinical Chemistry. $5^{\text {th }}$ ed. Philadelphia, USA: Saunders; 2001: 603.

3. Prockop LD, Chichkova RI. Carbon monoxide intoxication: An updated review. J Neurol Sci. 2007; 262 (1-2): 122-130. doi: 10.1016/j.jns.2007.06.037

4. Anderson J, Menkedick JR, Wooton MA. Healthy Homes Issues: Carbon Monoxide. US Department of Housing and Urban Development. 2005; 3: 1-35. 
glutathione $S$ transferase enzymes in the lung of rats supplemented with natural products. Br J Pharmacol Toxicol. 2013; 4(4): 136-141. doi: 10.19026/bjpt.4.5391

6. Emeka EO. Development crisis of power supply and implications for industrial sector in Nigeria. Studies Tribes and Tribals. 2008; 6(2): 83-92. doi: 10.1080/0972639X.2008.11886580

7. Ubani EC. Power sector reform, system reliability and successful power delivery in Nigeria. West African Journal of Industrial and Academic Research. 2012; 3(1): 114-122.

8. Mayne PD. Clinical Chemistry in Diagnosis and Treatment. $6^{\text {th }} \mathrm{ed}$. ELST; 2002: 96-188.

9. Agoro ES, Akubugwo EI, Chinyere GC, Alabrah PW, Ombor JA. The cumulative effects of chronic carbon monoxide inhalation on serum and vitreous protein and lipid panels. American Journal of Research Communication. 2018; 6(8): 20-32.

10. Agoro ES, Wankasi MM. Adikime N. Studies on serum proteins concentrations in pregnant women in bayelsa state. Journal of Medical Laboratory Science. 2013; 22(1): 49-57.

11. Stephen RT, Veena MB, Tatyana MM, Kevin RH, Christopher JL, David SL, et al. Plasma biomarkers in carbon monoxide poisoning. Clinical and Toxicology (Phila). 2010; 48(1): 47-56. doi: $10.3109 / 15563650903468209$

12. Chen KC, McGrath JJ. Response of the isolated heart to carbon monoxide and nitrogen anoxia. Toxicology and Applied Pharmacology. 1985; 81: 363-370. doi: 10.1016/0041-008X(85)90408-9

13. Thomsen HD. Carbon monoxide-induced atherosclerosis in primates. An electron-microscopic study on the coronary arteries of Macaca trusmonkeys. Atherosclerosis. 1974; 20: 233-240. doi: 10.1016/0021-9150(74)90008-2

14. Sarma JSM, Tillmanns H, Ikeda S, Bing RJ. The effect of carbon monoxide on lipid metabolism of human coronary arteries. Atherosclerosis. 1975; 22: 193-198. doi: 10.1016/0021-9150(75)90002-7

15. Siggaard-Andersen J, Kjeldsen K, Petersen FB, Astrup P. A possible connection between carbon monoxide exposure, capillary filtration rate and atherosclerosis. Preliminary report. Acta Medica Scandinavica. 1967; 182: 397-399. doi: 10.1111/j.0954-6820.1967. tb11540.x

16. Adams KF, Koch G, Chatterjee B, Goldstein GM, O'Neil JJ, Bromberg PA, et al. Acute elevation of blood carboxyhemoglobin to $6 \%$ impairs exercise performance and aggravates symptoms in patients with ischemic heart disease. J Am Coll Cardiol. 1988; 12(4): 900-999. doi: 10.1016/0735-1097(88)90452-4

17. Allred EN, Bleecker ER, Chaitman BR, Dahms TE, Gottlieb SO, Hackney JD, et al. Short-term effects of carbon monoxide exposure on the exercise performance of subjects with coronary artery disease. N Engl J Med. 1990; 322: 1426-1432. doi: 10.1056/ NEJM198911233212102

18. Egwurugwu JN, Nwafor A, Chinko BC, Oluronfemi OJ, Iwuji SC, Nwankpa P. Effects of prolonged exposure to gas flares on the lipid profile of humans in the Niger delta region, Nigeria. American Journal of Research Communication. 2013; 1(5): 115-145.

19. Alcindor LG, Belegaud J, Aalam H, Piot MC, Heraud C, Boudene C. Low-density lipoprotein cholesterol concentrations in hypercholesterolemic rabbits with or without carbon monoxide poisoning. Annal of Nutrition and Metabolism. 1984; 28(2): 117-122.

20. Agoro ES, Wankasi MM, Ombor OJ. Biochemical patterns of cardio-renal biomarkers in serum and vitreous humor of rabbits after chronic CO exposure. Ann Environ Sci Toxicol. 2019a; 3(1): 1-6. doi: 10.17352/aest.000017

21. Palmiere C, Mangin P. Postmortem chemistry update part 1. Int J Legal Med. 2012; 126: 187-198. doi: 10.1007/s00414-011-0625-y

22. Madea B, Musshoff F. Postmortem chemistry. Forensic Sci Int. 2007; 165(2-3): 165-117. doi: 10.1016/j.forsciint.2006.05.023

23. Agoro ES, Wankasi MM, Azuonwu O. The forensic application of vitreous humour biochemistry in postmortem disease diagnosis. Indian Journal of Forensic Medicine and Toxicology. 2017b; 11(1): 195199. doi: 10.5958/0973-9130.2017.00040.8

24. American Society of Nuclear Cardiology. Five Things Physicians and Patients Should Question, Choosing Wisely: an initiative of the ABIM Foundation, American Society of Nuclear Cardiology. 2012. Website. http://www.choosingwisely.org/societies/ american-society-of-nuclear-cardiology/. Accessed November 3, 2020.

25. Hendel RC, Berman DS, Di Carli MF, Heidenreich PA, Henkin RE, Pellikka PA, et al. ACCF/ASNC/ACR/AHA/ASE/SCCT/ SCMR/SNM 2009 appropriate use criteria for cardiac radionuclide imaging: A report of the American College of Cardiology Foundation appropriate use criteria task force, the American Society of Nuclear Cardiology, the American College of Radiology, the American Heart Association, the American Society of Echocardiography, the Society of Cardiovascular Computed Tomography, the Society for Cardiovascular Magnetic Resonance, and the Society of Nuclear Medicine. J Am Coll Cardiol. 2009; 53(23): 22012229. doi: 10.1016/j.jacc.2009.02.013

26. Whang SH, Choi IS. Studies on the clinical and laboratory findings of acute carbon monoxide intoxication. Journal of Korean Medical Association. 1990; 33: 997-1005.

27. Davutoglu V, Gunay N, Kocoglu H, Gunay NE, Yildirim C, Cavdar M, Tarakcioglu M. Serum concentrations of NT-ProBNP as an early cardiac marker of carbon monoxide poisoning. Inhal Toxicol. 2006; 18(2):155-158. doi: 10.1080/08958370500305885 
28. Agoro ES, Wankasi MM. The effects of chronic carbon monoxide intoxication on some liver biochemical parameters in rabbits. Journal of Indian Society of Toxicology. 2018b; 14(2): 12-16. doi: 10.31736/jist/v14.i2.2018.12-16

29. Schafer FQ, Buettner GR. Redox environment of the cell as viewed through the redox state of the glutathione disulfide/glutathione couple. Free Radical Biology and Medicine. 2001; 30(11): 1191 212. doi: 10.1016/s0891-5849(01)00480-4

30. Valko M, Morris H, Cronin MT. Metals, toxicity and oxidative stress. Curr Med Chem. 2005; 12(10): 1161-1208. doi: $10.2174 / 0929867053764635$

31. Evans MD, Cooke MS. Factors contributing to the outcome of oxidative damage to nucleic acids. Bioessays. 2004; 26(5): 533-542. doi: 10.1002/bies.20027

32. Agoro ES, Ombor JA, Alabrah PW, Tommy EO. The chronic influence of carbon monoxide intoxication on lipid peroxidation. Journal of Environmental Research. 2019b; 3(1): 1-6.

33. Ismail MM, El-Ghamry H, Shaker OG, Fawzi MM, Ibrahim SF. Some biomarkers in carbon monoxide-induced cardiotoxicity. Journal of Environmental Analytical Toxicology. 2013; 3: 176. doi: 10.4172/2161-0525.1000176

34. Thom, S.R., Bhopale, V.M., Han, S.T., Clark, J.M. and Hardy, K.R. Intravascular neutrophil activation due to carbon monoxide poisoning. Am J Respir Crit Care Med. 2006; 174: 1239-1248. doi: 10.1164/rccm.200604-557OC

35. Guan L, Zhang YL, Wen T, Wang XF., Zhu, M.X., Zhao J-Y. Dynamic changes of heme oxygenase- 1 in the hippocampus of rats after acute carbon monoxide poisoning. Arch Environ Contam Toxicol. 2011; 60: 165-172. doi: 10.1007/s00244-010-9524-3

36. Patel AP, Moody AJ, Sneyd JR, Handy RD. Carbon monoxide exposure in rat heart: Evidence for two modes of toxicity. Biochemical and Biophysical Research Communications. 2004; 321: 241-246. doi: 10.1016/j.bbrc.2004.06.124

37. Piantadosi CA, Carraway MS, Suliman HB. Carbon monoxide, oxidative stress, and mitochondrial permeability pore transition. Free Radical and Biological Medicine. 2006; 40: 1332-1339. doi: 10.1016/j.freeradbiomed.2005.11.020

38. Hamed S, Brenner B, Aharon A, Daoud D, Roguin A. Nitric oxide and superoxide dismutase modulate endothelial progenitor cell function in type 2 diabetes mellitus. Cardiovasc Diabetol. 2009; 8: 56. doi: 10.1186/1475-2840-8-56

39. Kavakli HS, Erel O, Delice O, Gormez G, Isikoglu S, Tanriverdi F. Oxidative stress increases in carbon monoxide poisoning patients. Human Experimental Toxicology. 2011; 30: 160-164. doi: $10.1177 / 0960327110388539$

40. Ochei J, Kolhatkar A. Haematology. In: Medical Laboratory Sci- ence Theory and Practice. NY, USA: Tata McGraw-Hill; 2003: 251.

41. McClatchey KD. Clinical Laboratory Medicine. Philadelphia, USA: Lippincott Williams and Wilkins; 2002: 288.

42. Mengel MB, Schwiebert LP. Family medicine: Ambulatory care \& prevention. NY, USA: McGraw-Hill Professional; 2005: 268.

43. Nanji AA, Jui LT, French SW. Effect of chronic carbon monoxide exposure on experimental alcoholic liver injury in rats. Life Sciences. 1989; 45(10): 885-890. doi: 10.1016/0024-3205(89)90202-6

44. Niebró,J T, Gruszczyńska M. Experimental studies of the effect of carbon monoxide on the retina of guinea pigs of different age. Klin Oczna, 1992; 94(4): 81-82.

45. Stefan WR, Danielle M, Augustine MK. Carbon monoxide and bilirubin potential therapies for pulmonary/vascular injury and disease. Am J Respir Cell Mol Biol. 2007; 36(2): 175-182. doi: 10.1165/rcmb.2006-0333TR

46. Ryter SW, Alam J, Choi AM. Heme oxygenase-1/carbon monoxide: from basic science to therapeutic applications. Physiol Rev. 2006; 86: 583-650. doi: 10.1152/physrev.00011.2005

47. Zuckerbraun BS, Billiar TR, Otterbein SL, Kim PKM, Liu F, Choi AMK, et al. Carbon monoxide protects against liver failure through nitric oxide-induced heme oxygenase-1. J Exp Med. 2003; 198: 1707-1716.

48. Carlson GP. Clinical chemistry tests. In: Smith BP, ed. Internal Animal Medicine. $2^{\text {nd }}$ ed. NY, USA: Mosby Publishers; 1996.

49. Wang X, Wang X, Wen T, Guan L, Zhang Y, Zhu M, Zhao J. Hemorheological changes in cerebral circulation of rabbits with acute carbon monoxide poisoning. Clin Hemorheol Microcirc. 2009; 43(4): 271-282. doi: 10.3233/CH-2009-1239

50. Anandha Lakshmi S, Lakshmanan A, Ganesh KP, Saravanan A. Effect of intensity of cigarette smoking on haematological and lipid parameters. Journal of Clinical and Diagnosis Research. 2014; 8(7): $11-13$.

51. Muhammad IK, Mulazim HB, Muhammad S, Sharmaine B. Effect of smoking on red blood cells count, haemoglobin concentration and red cell indice. Pakistan Journal of Medical and Health Sciences. 2014; 8(2): 361 .

52. Vanuxem D, Sampol J, Weiller PJ, M'Bark J, Grimand C. Influences du tabagisme chronigue sur les leukocytes. Respiration. 1984; 46: $258-264$.

53. Whang SH, Choi IS. Studies on the clinical and laboratory findings of acute carbon monoxide intoxication. Journal of Korean Medical Association. 1990; 33: 997-1005.

54. Sung-Soo L, II-Saing C. Haematological changes in acute carbon monoxide intoxication. Yonsei Medical Journal. 1994; 35(3): 245 
259. doi: 10.3349/ymj.1994.35.3.245

55. Suphans S, Viroj W, Jamsai S. Blood carboxyhaemoglobin concentration and platelets: A correlation study. Clin Appl Thromb Hemost. 2004; 10(3): 281-283. doi: 10.1177/107602960401000312

56. Oscar AG. Carbon monoxide inhibits capacitative calcium entry in human platelets. Thrombosis Research. 2004; 114: 113-119. doi: 10.1016/j.thromres.2004.04.015

57. Brüne B, Ullrich V. Inhibition of platelet aggregation by carbon monoxide is mediated by activation of guanylate cyclase. Mol Pharmacol. 1987; 32(4): 497-504.

58. Penney DG, Bishop PA. Hematologic changes in the rat during and after exposure to carbon monoxide. Journal of Environmental Pathology and Toxicology. 1978; 2(2): 407-415.

59. Agoro ES, Wankasi MM, Zebedee UL, Agoro E-Y. The effects of chronic carbon monoxide intoxication on some haematological parameters and films in rabbits. Adv J Toxicol Curr Res. 2019; 3(1): $1-5$. 